\title{
Comparative assessment of cucumber hybrids of semko-junior company by yield in the taiga zone of Omsk region
}

\author{
Alyona Krasovskaya ${ }^{1}$, Maria Krasovskaya ${ }^{2}$, Vladimir Kumpan ${ }^{1}$, and Anna Kling ${ }^{1}$ \\ ${ }^{1}$ Omsk State Agrarian University named after P.A. Stolypin, Institutskaya Square, 1, Omsk, 644008, Russia \\ ${ }^{2}$ Omsk State Medical University, Lenin street, 12, Omsk, 644099, Russia
}

\begin{abstract}
Comparative assessment of cucumber hybrids of a Semko-Junior farm firm located in a taiga zone of Omsk Region showed that on average over 2 years the cucumber hybrids - F1 Otello and F1 Lastochka - which button stage was noted 2 days earlier in comparison with ultra-early F1 Tviksi and 1 day earlier in comparison with the control sample, were the most early-ripening variety. The longest period of "seedling-button stage" - 46 days - was characteristic of the hybrids F1 Semkross and F1 Kaskader. F1 Otello hybrid gave the highest total $\left(7.53 \mathrm{~kg} / \mathrm{m}^{2}\right)$ and commercial yield $\left(7.10 \mathrm{~kg} / \mathrm{m}^{2}\right)$, as well as early products yield. On average over 2 years the highest percentage of commercial yield - 93.9 was obtained with F1 Otello hybrid, the lowest - 84.6 - with F1 Semkross hybrid. In 2016, the highest yield $60.5 \%$ of the total amount was harvested with regard to F1 Otello by August 9, more than $50 \%$ of the total yield was obtained from F1 Orlenok and F1 Lastochka, which also indicates their early ripening. In 2017, fruiting was later due to weather conditions, and by August 21 F1 Otello gave more than $50 \%$ of the yield, which confirmed its early ripening. The highest tasting assessment of buttons in fresh form was obtained for F1 Lastochka and F1 Otello. In the conditions of the taiga zone of Omsk Region, cucumber hybrids of the Semko-Junior farm firm - F1 Otello, as well as F1 Lastochka, which are distinguished by high yields and flavors, are recommended for vegetable growers to ensure early production and high yield.
\end{abstract}

\section{Introduction}

Supplying the population with all types of vegetables is the main task of vegetable production. In terms of its popularity, cucumber ranks third among vegetable crops after cabbage and tomato. The main commercial production of cucumber in open ground is concentrated in the southern regions of Russia and the Central Chernozem Region. In vegetable farms of Omsk Region cucumber is grown in winter and spring plastic film greenhouses, as well as in open ground, its variety testing is carried out [6].

If the right variety is chosen, it is possible to succeed in growing cucumbers [4]. Today, experts recommend growing F1 hybrids, early and high-yielding varieties of cucumber that have no bitterness and a predominant number of female flowers or self-pollinating species [7]. Their advantage is that they are much more productive and have complex resistance to several main cucumber diseases at once (powdery and false mildew, cucumber scab, tobacco mosaic virus, root rot). All modern hybrids intended for amateur vegetable growers are usually early ripening, most of them may be grown both in open and protected soil. Besides, hybrids are able to withstand long-term reduced positive air temperatures and are quite resistant to sharp daily fluctuations [8]. Thus, the correct choice of variety is one of the most important conditions for obtaining high cucumber yields in all regions [12].
The set of varieties and hybrids of cucumber is expanding every year. Most the selection creations are of Russian origin [5], so it is necessary to study them in various soil and climatic conditions.

The variety testing of vegetable crops, including cucumber, is carried out in Omsk Region at Omsk vegetable state site on irrigation, where the sum of temperatures for the vegetation period is bigger, and the daily mean air temperature is higher, the vegetation period is longer by 10-15 days [1] than in the taiga zone of Omsk Region. Therefore, the study of cucumber varieties in open ground in the taiga zone of Omsk Region seems quite relevant.

Purpose of the study: to give a comparative assessment of the cucumber hybrids of the Semko-Junior farm firm by yield in the taiga zone of Omsk Region.

\section{Research methods}

The studies were carried out in 2016-17 in the taiga zone of Omsk Region on gray forest soil as part of a competition together with the State Funded Extended Educational Institution "Tarsky Station of Young Naturalists". The experimental soil was neutral ( $\mathrm{pH}$ 6.7) with increased phosphorus content $(302 \mathrm{mg} / \mathrm{kg}$ ) and average potassium content $(180 \mathrm{mg} / \mathrm{kg})$ according to Kirsanov's soil grouping $[9,14]$, i.e. quite favorable for cucumber cultivation.

\footnotetext{
Corresponding author: krasovaw@ mail.ru
} 
The northern regions of Omsk Region, which includes Tarsky, are characterized by lower air temperatures than the rest of the region. The frost-free period on average lasts 100-115 days with significant deviations from the average in some years from 70 to 150 days. Freezing on average falls on May 24-26, and in some years with friendly and warm weight the frosts stop earlier than the average multi-year dates by one month (April 23). The latest frosts are observed on June 11. The first frosts in autumn are observed on average on September 10-20. The earliest frosts are observed on August 11.

The sum of mean daily temperatures over the period above $10{ }^{\circ} \mathrm{C}$ is $1650-1850{ }^{\circ} \mathrm{C}$. According to the average long-term data, the annual rainfall is $360-430 \mathrm{~mm}$, for the warm period (April-October) - from 300 to $360 \mathrm{~mm}$ and for the period with a stable mean daily temperature above $10{ }^{\circ} \mathrm{C}$ (period of active vegetation) - from 220 to $250 \mathrm{~mm}$ [1]. The hydrothermal coefficient is 1.3-1.5, which is an indicator of sufficient moisture availability during the period of active vegetation. This means that in the taiga zone the temperatures are enough to grow early-ripening cucumber hybrids in open ground.

Weather conditions of the vegetation period of 2016 from the third decade of May to the second decade of August inclusive differed from the average multi-year data of a higher mean daily temperature [2], which favorably affected the growth and development of cucumber. The mean daily temperature for June-August was $18.8{ }^{\circ} \mathrm{C}$, which is $2.8^{\circ} \mathrm{C}$ higher than the average long-term data, $203.3 \mathrm{~mm}$ of precipitation fell, which amounted to $95.8 \%$ of the norm. In general, summer was hot and dry, and weather conditions in 2016 were favorable for the growth, development and fruiting of cucumber.

In 2017, from June to August inclusive, the mean daily temperature was $17.2{ }^{\circ} \mathrm{C}$, i.e. only $0.3{ }^{\circ} \mathrm{C}$ warmer compared to the average multi-year data and $1.6{ }^{\circ} \mathrm{C}$ colder compared to 2016. Precipitation fell more than the norm and the previous year of study - $329.9 \mathrm{~mm}$ [3]. Weather features affected the growth, development and yield of cucumber.

Object of study: ultra-early and early-ripening hybrids of cucumber of the Semko-Junior farm firm: F1 Otello, F1 Tviksi, F1 Orlenok (control), F1 Semkross, F1 Artek, F1 Lastochka, F1 Kaskader.

Experimental agricultural methods. The preceding crop was cabbage. The main tillage was carried out in fall to a depth of $18-20 \mathrm{~cm}$. Harrowing was performed in spring, intermediate tillage to a depth of $13-15 \mathrm{~cm}$, and tillage before sowing to a depth of 5-6 cm. Sowing was carried out on May 27 in 2016 and on May 30 in 2017 so that plants do not freeze. The planting width $-70 \mathrm{~cm}$, the distance between the seeds in a row $-10 \mathrm{~cm}$, the sowing depth $-3-4 \mathrm{~cm}$. Sowing included weeding, loosening and watering, if necessary. Harvesting of buttons was carried out in 2-3 days.

The studies were carried out according to the state variety test method [11].

Tasting of fresh buttons was carried out without salt and bread. Taste qualities are evaluated according to a five-point scale: very tasty -5 , tasty -4 , medium-tasty -
3 , tasteless -2 , very tasteless -1 . During tasting, the presence of bitterness in the fruits, the appearance of buttons, the size of seed vessels and other signs that the taster considered necessary were noted [15]. Mathematical processing of data [10] was carried out using Statist software.

\section{Results}

The observations of cucumber growth and development showed that full seedlings of all cucumber hybrids in 2016 appeared on June 12 after an increase in the mean daily temperature in the third decade of June. The duration of the "sowing-seedlings" period was 15 days. In 2017, the seedlings of all hybrids appeared after an increase in air temperature in mid-June - June 16, which was 17 days after sowing, i.e. the duration of the sowingseedling period was more than 2 days, which is associated with a cooler mean daily temperature in the first decade of June. On average, over 2 years, the duration of the sowing-seedling period for all hybrids was 16 days. The flowering stage of cucumber depending on the hybrid was observed on July 14-18 in 2016 and on July 17-20 in 2017.

In 2016 the period from seedling to a button stage was the shortest for F1 Otello and F1 Lastochka and amounted to 40 days. The longest -44 days, which was noted in F1 Semkross, F1 Kaskader and F1 Tviksi. In 2017, this period was the shortest for F1 Tviksi and F1 Otello - 45 days. The longest -47 days was for F1 Orlenok, F1 Semkross and F1 Kaskader. On average, over 2 years, F1 Lastochka and F1 Otello showed the earliest fruiting - after 43 days, which is very important in the conditions of the taiga of Western Siberia. The period from seedlings to a button stage was the longest for F1 Semkross and F1 Kaskader and lasted 46 days.

The fruiting period of cucumbers is quite long and is 20-90 days. It is the largest among the southern varieties "accustomed" to a long frost-free period. Fruiting in northern varieties is shorter, usually interrupted by early autumn frosts or simply a sharp decrease in temperature, causing diseases and plant death [4].

In our experiments in 2016, by the last harvest (August 23), the leaves of F1 Tviksi and F1 Otello became yellow-brown, F1 Semkross, F1 Kaskader, F1 Lastochka and F1 Orlenok (k) - yellow, and only F1 Artek - remained green. In 2017, by the end of August, F1 Otello began to turn yellow, and by the last harvest on September 4, all hybrids began to turn yellow due to cooling in early September.

Thus, phenological observations showed that in the conditions of the taiga of Omsk Region on average over 2 years of study the cucumber hybrids F1 Otello and F1 Lastochka were the earliest, at which the button stage was noted 2 days earlier in comparison with ultraearly F1 Tviksi (as it is specified in the description of a hybrid) and 1 day earlier in comparison with the control. The longest period of "seedling-button stage" - 46 days was in F1 Semkross and F1 Kaskader.

The analysis of the yield of cucumber hybrids showed that depending on the year it ranged from 4762.1 
(Kaskader) to $8252.5 \mathrm{~g} / \mathrm{m}^{2}$ (Otello) in 2016. In 2017, the highest yield was observed in F1 Tviksi and F1 Otello hybrids, the difference between which was insignificant (Table 1).

Table 1. Yield of cucumber hybrids, $\mathrm{g} / \mathrm{m}^{2}$

\begin{tabular}{|c|l|c|c|c|}
\hline $\mathrm{n} / \mathrm{n}$ & \multicolumn{1}{|c|}{ Variety } & 2016 & 2017 & Average over 2 years \\
\hline 1 & F1 Orlenok $(\mathrm{k})$ & 4906.8 & 3690.4 & 4298.6 \\
\hline 2 & F1 Semkross & 4592.4 & 5203.3 & 4897.9 \\
\hline 3 & F1 Artek & 6030.4 & 5866.0 & 5948.2 \\
\hline 4 & F1 Lastochka & 6612.7 & 6464.4 & 6538.6 \\
\hline 5 & F1 Kaskader & 4762.1 & 5315.9 & 5039.0 \\
\hline 6 & F1 Tviksi & 5058.7 & 7211.1 & 6134.9 \\
\hline 7 & F1 Otello & 8252.5 & 6812.8 & 7532.7 \\
\hline & HCP 05 & 620 & 452 & \\
\hline
\end{tabular}

On average over 2 years a high yield $-7532.7 \mathrm{~g} / \mathrm{m}^{2}$ was observed in F1 Otello hybrid, in the control version F1 Orlenok it turned out to be the lowest.

A higher percentage of commercial buttons was formed in all hybrids in warmer 2016. The highest percentage - 97.0 and 96.8 was in F1 Artek and F1 Otello, respectively (Table 2). F1 Semkross (90.6\%) and
F1 Kaskader $(90.1 \%)$ had the lowest percentage of commercial fruits. In 2017, F1 Otello (91.0\%) F1 Orlenok (90.5\%) had the highest percentage of commercial fruits, F1 Semkross - the lowest $-78.6 \%$. On average over 2 years F1 Otello gave the highest percentage of commercial products - 93.9, while F1 Semkross - the lowest - 84.6.

Table 2. Commercial yield

\begin{tabular}{|l|l|c|c|c|c|c|c|}
\hline \multirow{2}{*}{$\mathrm{n} / \mathrm{n}$} & \multicolumn{1}{|c|}{ Hybrid } & \multicolumn{3}{|c|}{ \% commercial fruits } & \multicolumn{3}{c|}{ Commercial yield, $\mathrm{kg} / \mathrm{m}^{2}$} \\
\cline { 3 - 7 } & & 2016 & 2017 & average & 2016 & 2017 & average \\
\hline 1 & F1 Orlenok (k) & 95.1 & 90.5 & 92.8 & 4.67 & 3.34 & 4.01 \\
\hline 2 & F1 Semkross & 90.6 & 78.6 & 84.6 & 4.16 & 4.09 & 4.13 \\
\hline 3 & F1 Artek & 97.0 & 80.2 & 88.6 & 5.85 & 4.70 & 5.28 \\
\hline 4 & F1 Lastochka & 92.9 & 88.4 & 90.7 & 6.14 & 5.71 & 5.93 \\
\hline 5 & F1 Kaskader & 90.1 & 86.5 & 88.3 & 4.29 & 4.60 & 4.45 \\
\hline 6 & F1 Tviksi & 93.1 & 85.8 & 89.5 & 4.71 & 6.19 & 5.45 \\
\hline 7 & F1 Otello & 96.8 & 91.0 & 93.9 & 7.99 & 6.20 & 7.10 \\
\hline
\end{tabular}

Taking into account the total yield and output of commercial products, the highest yield of commercial buttons was in F1 Otello, and made $7.10 \mathrm{~kg} / \mathrm{m}^{2}$. The lowest yield of commercial products was in F1 Orlenok, which was taken for control.

For the conditions of the taiga zone, it is important to obtain early cucumber production in open ground, since in some years frosts were very early. The earliest are observed on August 11. In our experiment in 2016, the highest harvest $-60.5 \%$ of the total amount was collected by August 9 from F1 Otello hybrid (Table 3), more than $50 \%$ of the total harvest was obtained from F1 Orlenok and F1 Lastochka, which also indicates their early ripening. By August 13, more than 70\% of the total yield was obtained from F1 Otello and F1 Orlenok, and by August 20 the largest percentage of the yield was also harvested from F1 Otello hybrid. The lowest percentage of all yield by August 9 and 13 was noted in F1 Semkross, which under our conditions was the latest.

Table 3. Yield by harvest dates in $2016, \%$ of total yield

\begin{tabular}{|l|l|c|c|c|c|c|}
\hline $\mathrm{n} / \mathrm{n}$ & \multicolumn{1}{|c|}{ Hybrid } & August 9 & August 13 & August 16 & August 20 & August 23 \\
\hline 1 & F1 Orlenok (k) & 54.3 & 70.9 & 87.2 & 95.0 & 100 \\
\hline 2 & F1 Semkross & 36.8 & 52.5 & 77.4 & 95.0 & 100 \\
\hline 3 & F1 Artek & 46.3 & 58.3 & 78.3 & 95.7 & 100 \\
\hline 4 & F1 Lastochka & 51.4 & 64.1 & 80.4 & 93.7 & 100 \\
\hline 5 & F1 Kaskader & 47.0 & 59.6 & 76.2 & 95.6 & 100 \\
\hline 6 & F1 Tviksi & 54.8 & 64.7 & 81.5 & 95.5 & 100 \\
\hline 7 & F1 Otello & 60.5 & 72.6 & 90.0 & 96.8 & 100 \\
\hline
\end{tabular}


In 2017, fruiting was later due to weather conditions, and by August 21, F1 Otello hybrid gave more than 50\% of the yield (Table 4), which confirms its early ripening.
It should be noted that the yield was more uniform, which is also very important.

Table 4. Yield by harvest dates in $2017, \%$ of total yield

\begin{tabular}{|l|l|c|c|c|c|c|}
\hline $\mathrm{n} / \mathrm{n}$ & \multicolumn{1}{|c|}{ Hybrid } & August 21 & August 24 & August 28 & August 31 & September 4 \\
\hline 1 & F1 Orlenok (k) & 44.5 & 69.8 & 81.4 & 97.0 & 100 \\
\hline 2 & F1 Semkross & 40.0 & 53.8 & 86.5 & 90.2 & 100 \\
\hline 3 & F1 Artek & 39.4 & 69.8 & 86.4 & 95.0 & 100 \\
\hline 4 & F1 Lastochka & 38.6 & 55.7 & 78.3 & 91.8 & 100 \\
\hline 5 & F1 Kaskader & 37.0 & 57.7 & 80.4 & 92.1 & 100 \\
\hline 6 & F1 Tviksi & 46.0 & 65.2 & 86.5 & 95.3 & 100 \\
\hline 7 & F1 Otello & 50.9 & 67.6 & 85.6 & 97.6 & 100 \\
\hline
\end{tabular}

The tasting assessment showed that F1 Otello and F1 Lastochka hybrids were the best in taste and received a score of 5 points on average over 2 years. The lowest score -4.3 points - was given to $F 1$ Kaskader.

Thus, F1 Otello turned out to be the earliest-ripening and highest-yielding variety in our conditions. This hybrid also gave the highest commercial yield and was distinguished by excellent flavors.

\section{Practical relevance}

In order to increase the yield of high-quality, environmentally friendly cucumber hybrids in open ground, early-ripening cucumber hybrids for open ground were identified and recommended to vegetable growers.

\section{Conclusion}

The studies showed that the cucumber hybrids F1 Otello and F1 Lastochka are the most early-ripening, in which the button stage was noted earlier by 2 days compared to the ultra-early F1 Tviksi and 1 day earlier compared to the control. The longest period of the "seedling-button" stage - 46 days was in F1 Semkross and F1 Kaskader.

F1 Otello has the highest total $\left(7.53 \mathrm{~kg} / \mathrm{m}^{2}\right)$ and commercial $\left(7.10 \mathrm{~kg} / \mathrm{m}^{2}\right)$ yields. F1 Lastochka and F1 Otello received a high tasting score of their fresh buttons.

In the conditions of the taiga zone of Omsk Region, cucumber hybrids of the Semko-Junior farm firm - F1 Otello, as well as F1 Lastochka, which are distinguished by high yields and flavors, are recommended for vegetable growers to ensure early production and high yield.

\section{References}

1. Agroclimatic handbook of Omsk Region. (Leningrad: Hydrometeoisdat, 1959)

2. Agrometeorological bulletins of GMS Tara of Omsk Region for May, June, July and August 2016.
3. Sh.G. Bekseev Vegetable cultures of the world. Encyclopedia of gardening. (St. Petersburg: Dilya, 1998)

4. V.F.Belik Cucumbers (in beds, in a greenhouse, in a room). (Moscow: Rural Novy Publishing house, 2001)

5. A. Borisov. Household, 4, 32-34, (2013)

6. A.P. Kling, Yu.A. Mikhailova, V.N. Kumpan, A.A. Gaivas Bulletin of Omsk State Agrarian University, 4 (32), 23-30, (2018)

7. L.V. Mitina Growing vegetables. (Moscow: LLC TD "Publishing House World of Books", 2008)

8. Z.Mikhaylova Orchard and garden, 3, 2-5, (2008)

9. L.N. Mishchenko Soils of Omsk Region and their agricultural use: educational manual (Omsk State Agricultural Institute, 1991)

10. V.F. Moiseichenko, M.F. Trifonova, A.Kh. Zaveryukha, V.E. Eshchenko, Fundamentals of scientific research in agronomy (Moscow: Kolos, 1996)

11. Methodology of state variety testing of crops. (Moscow, 1985).

12. Yu.K. Tulupov, E.G. Greenberg, S.S. Litvinov et al. Vegetable growing in Western Siberia (Moscow: Kolos, 1981)

13. V.D. Boyko (Ed.) Recommendations for cultivating crop varieties and the results of crop variety testing in Omsk Region for 2016 (Omsk, 2016)

14. P.M. Smirnov, E.A. Muravin, Agrochemistry (Moscow: Agropromizdat, 1991)

15. N.N. Timofeev, A.A. Volkova, S.T. Chizhov Selection and seed production of vegetable crops (Moscow: Arkhangelgiz, 1960). 